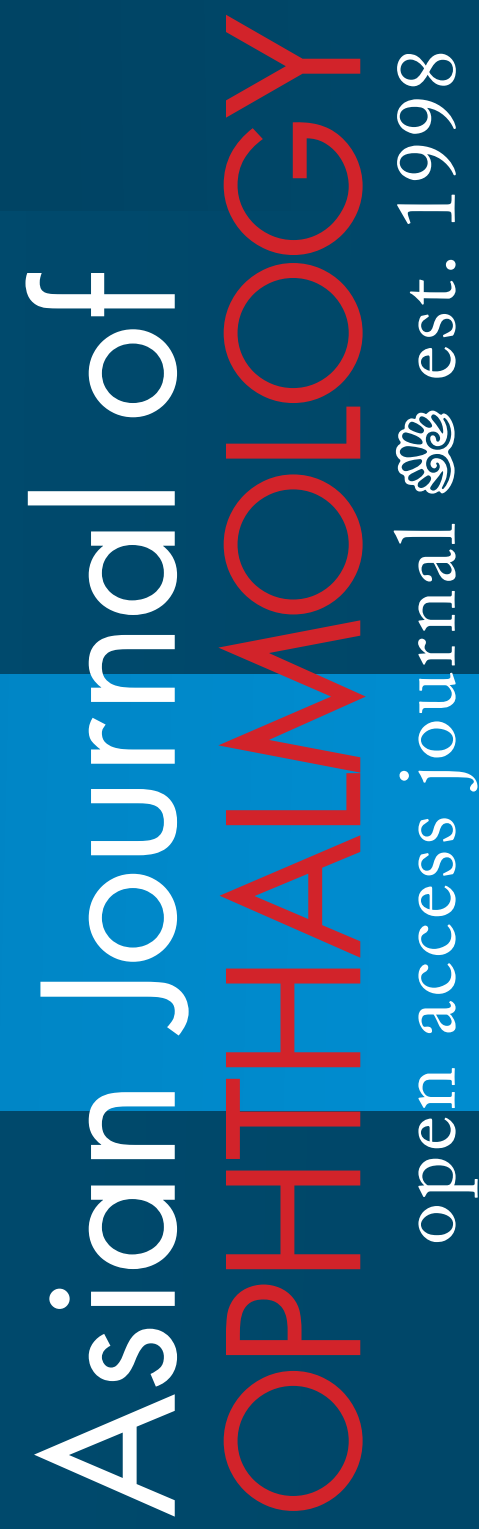

Volume $13 \cdot$ Issue $4 \cdot 2014 \cdot 1560-2133$ 


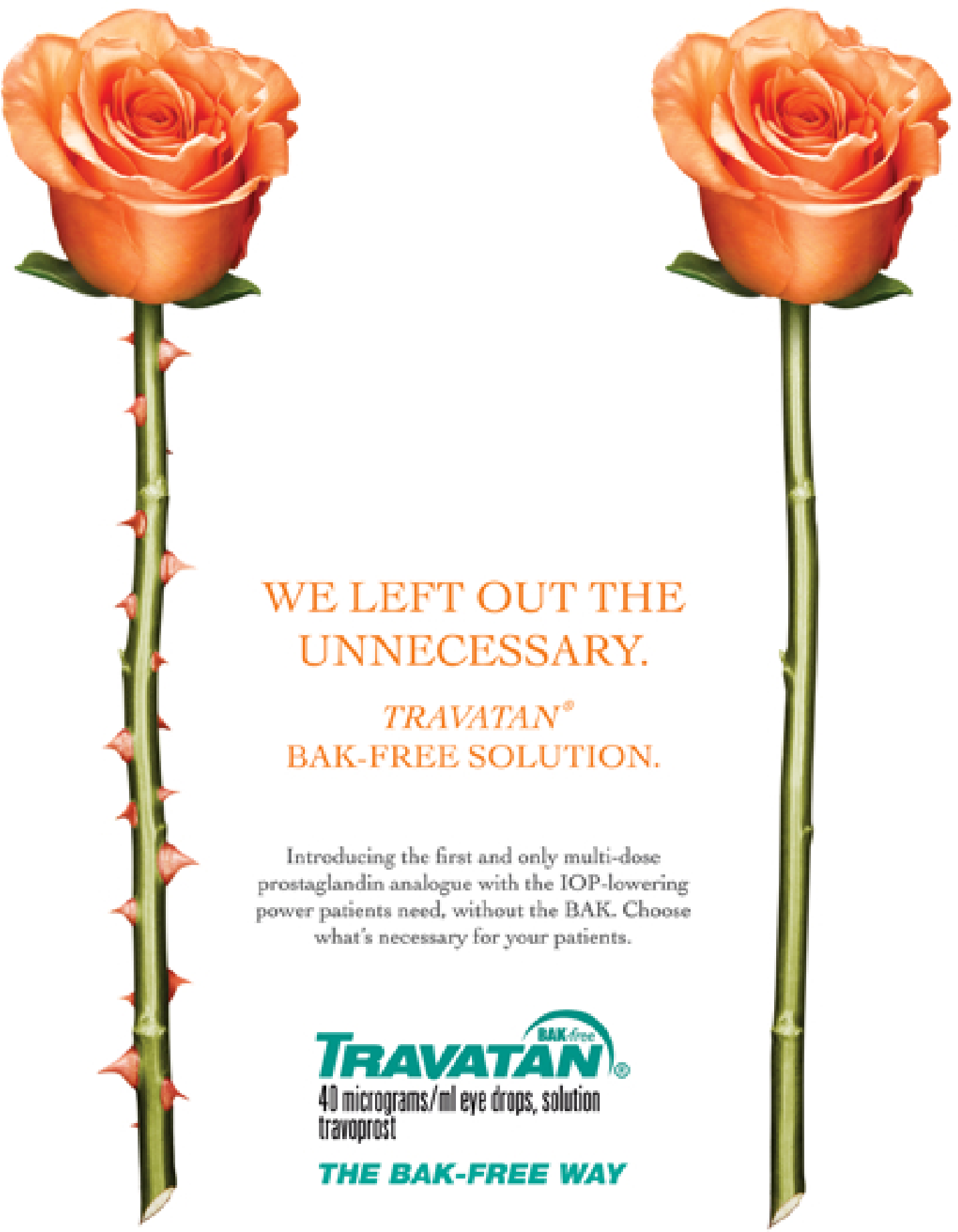

For more information on the product please contact your local Alcon' representative 


\section{Asian Journal of OPHTHALMOLOGY}

Submit your article now to the

Asian Journal of

a peer-reviewed online open access journal.

There are no publication costs, hidden fees or charges.

\section{Chief editor: Paul Chew}

The objectives of Asian Journal of Ophthalmology are as follows:

- To provide a platform for the publication of information with a focus on Ophthalmology in Asia

- To disseminate information that will improve the care of patients with all types of ophthalmological disorders, with a special focus on glaucoma

- To increase the understanding of such disorders through reporting of educational activities

- To publish the results of research programmes to expand knowledge about the causes, prevention, and treatment of ophthalmological disorders

- To work closely with Asian and international researchers to achieve these aims

- To provide a forum for young and relatively inexperienced researchers to present their research results as Original Articles via an international platform

- To maintain and promote relationships with any organisation with similar goals.

For more information, an article template and submission guidelines, see www.asjoo.com

PUBLICATION SCHEDULE 2014-2015:

2014

September 2014

September 2014

October 2014

December 2014

14-1

Highlights print issue

(APGC)

14-2

14-3
2015

February $2015 \quad$ 14-4: Special issue on

Generic Medications

April 2015

July 2015

October 2015

January 2016
15-1

15-2

15-3

15-4

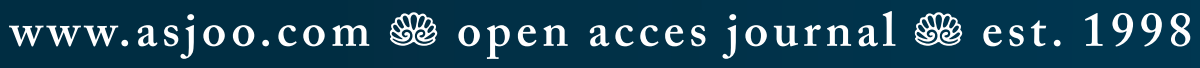




\title{
A case series of bilateral electric cataract in high-voltage electrical injury
}

\author{
K. Fariduddin, ${ }^{1}$ S. Samanta, ${ }^{2}$ C. Chakraborty ${ }^{2}$ \\ 'IIMSAR, Haldia, WB; ${ }^{2} \mathrm{CNMCH}$, Kolkata, WB, India
}

Key words: Electric cataract, lagophthalmos, chorioretinal lesion, subcapsular vacuoles, high-voltage electric current

\section{Introduction}

A 39 year-old female presented with progressive diminution of vision in the right eye for six months after sustaining an injury from a high-voltage electric current to the right side of her forehead, face, around the right eye and to the scalp. On examination with the slit lamp, the right eye showed a mature cataract and anterior subcapsular opacities, with early lental opacity in left eye. She suffered from lagophthalmos and slight conjunctival congestion in the right eye. Vision in the right eye was only perception of light and in the left eye accurate projection of rays and 6/24. From the history, the type of injury (wound of entry and exit), and slit-lamp examination confirmed a case of bilateral electric cataract. We performed manual smallincision cataract surgery with posterior chamber intraocular lens implantation in right eye and in the left eye, using local anesthesia. Postoperative visual acuity was only $3 / 20$ in the right eye and 6/6 in the left eye. In this case we have seen three circumscribed retinal lesions in the right eye; the left eye it was normal. This has been documented.

The second case was a 20-year-old male, who was admitted to our center with bilateral electric cataract. He was treated the same way as the first case. He regained normal BCVA after cataract surgery with posterior chamber intraocular lens implantation.

\section{Case report}

Case 1 is a 39-year-old female who presented to our outpatient department with painless, progressive dimness of vision in her right eye that started six months previously, and inability to close the right eye properly. She had suffered from a high-voltage electric injury about six months before, while she was doing her morning work in her own home. She had been unconscious for about 15 minutes and was admitted to a nearby private hospital in Tamluk, West Bengal, where she was given primary treatment.

Correspondence: Dr. Khandkar Fariduddin, Assistant Professor, Department of Ophthalmology, Malda Medical College and Hospital, Malda, WB, India.

E-mail: K33fariduddin@gmail.com 


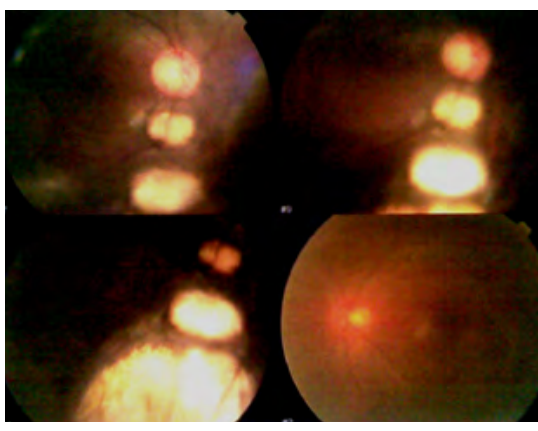

Fig. 1. Lagophthalmos (first case).

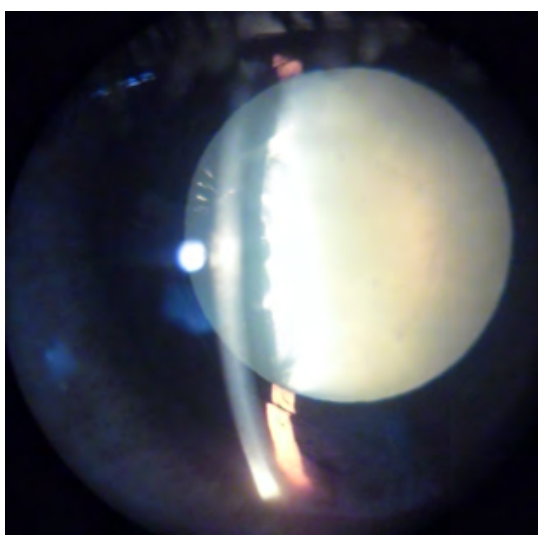

Fig. 2. Anterior subcapsular opacities.

On examination at our center there was lagophthalmos (Fig. 1) in the right eye due to severe scar tissue formation in the upper and lower lid. There was scar tissue on the forehead and the right side of her face and areas of alopecia and scarring on her scalp. Slit lamp examination showed a milky white lens (Fig. 2) with anterior subcapsular opacities. Conjunctiva was slightly congested in the right eye. Cornea, sclera, iris and anterior chamber were normal in both eyes. Ocular movement was full in both eyes. Visual acuity was only perception of light with accurate projection of rays in the right eye and 20/20 in the left eye. Upon examination with a direct ophthalmoscope, the dilated fundus of the left eye was within the normal limit and the dilated fundus of the right eye was obscured by lens opacity. Intraocular pressure was 14.0 $\mathrm{mmHg}$ in both eyes, measured by applanation tonometry.

After admission of the patient, we did all routine examinations. We then performed a correction of the lagophthalmos (Fig. 3) with the assistance from a plastic surgeon. After two weeks, we performed smallincision cataract surgery and posterior chamber intraocular lens implantation in the right eye under peribulbar anesthesia.

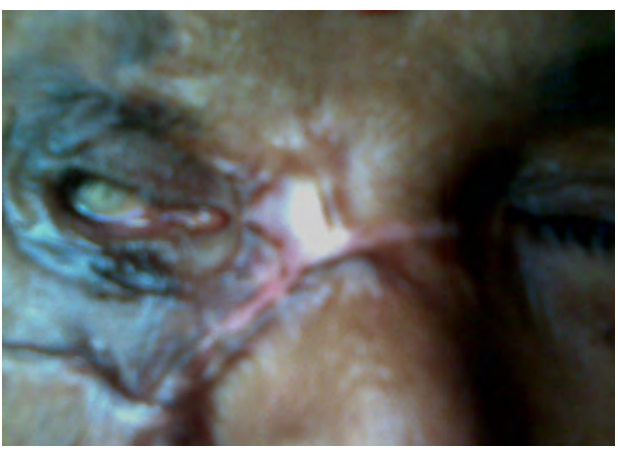

Fig. 3. Lagophthalmos after plastic reconstruction.

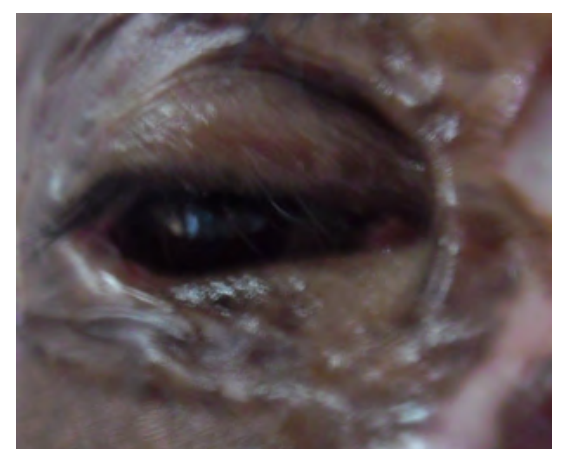

Fig. 4. Three circumscribed lesions in the retina of the right eye (first case). 
Surgery was successful and the patient's vision improved only to $3 / 20$ from PL postoperatively after two weeks. Before the electric injury, there was no evidence of diminished vision in both eyes. Thorough fundus examination by direct and indirect ophthalmoscope (+20D and +90D) revealed presence of three circumscribed chorioretinal lesions (Fig. 4) in the retina, starting from just below the fovea. We did fundus photography for documentation. The patient was referred to a retinologist for further evaluation and management of the case. After two months, the patient developed cataract in the left eye which was operated by the same method and vision was $20 / 20$ postoperatively with normal fundus findings.

Case 2 was a 20-year-old male patient who presented to our hospital with progressive dimness of vision in both eyes, but worse in the right eye than in the left eye. The patients had suffered electric injury on the right side of the scalp four months previously. Upon examination, vision was F.C $2 \mathrm{ft}$ in the right eye and 6/18 in the left eye. Slit lamp examination revealed anterior subcapsular vacuoles in both eyes. Fundus detail in right eye was not well seen and in left eye it was within normal limits. Other ocular findings are within normal limits. There was area of alopecia on the scalp of about $2 \times 3$ inches which indicated the wound of entry (Fig. 5) and scar marks in both feet indicating the exit wounds (Fig. 6). Patient underwent smallincision cataract surgery with posterior chamber intraocular lens implantation in the right eye and two months later in the left eye. The patient regained 6/6 BCVA in both eyes.

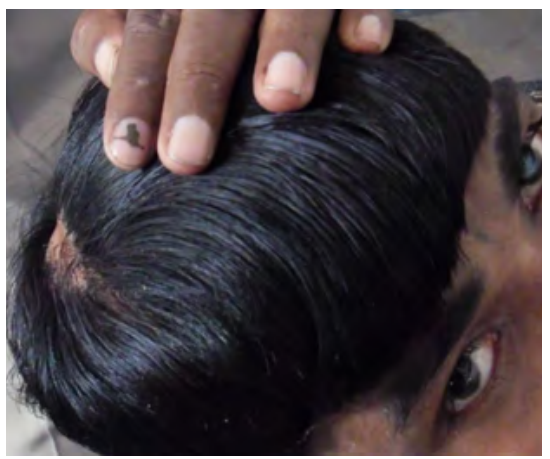

Fig. 5. Wound of entry. Alopecia with cataract.

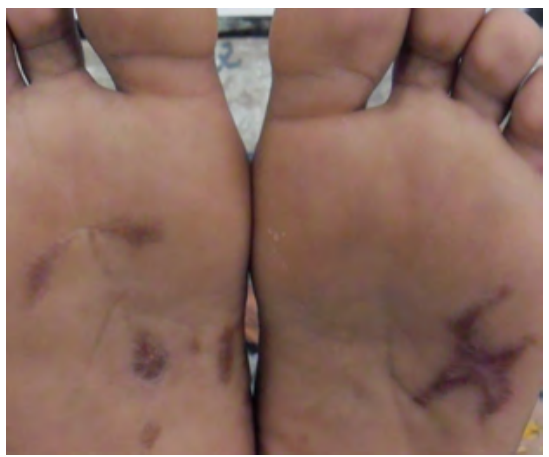

Fig. 6. Exit wounds.

\section{Discussion}

The progressively increasing dependence on electricity, unsafe wiring and hooking has resulted in a rise in injuries due to contact with electrical current. ' The earliest record of cataract development from lightning shock was made by Saint Yves in $1722 .{ }^{2}$ According to statistical data, $0.8-1 \%$ of all accidental deaths are caused by an electrical injury. ${ }^{3}$ Cataractogenesis following electrical trauma has been reported to occur with a latency period varying from immediately after injury to a few years after injury. ${ }^{4}$ The exact pathogenesis of the effect of electric current on the proteins 
of the crystalline lens and the process of lenticular opacification is unclear. ${ }^{5} \mathrm{Hess}^{6}$ and $\mathrm{Croci}^{7}$ proposed extensive epithelial damage as the cause of the lenticular opacities. Kiribuchi ${ }^{8}$ postulated that cataract was the result of uveitis and circulatory changes. Decreased permeability of the lens capsule, a direct coagulative effect on the proteins of the lens cells, powerful contraction of the ciliary muscle causing a concussion type of cataract due to mechanical damage, nutritional disturbances of the lens due to iritis and impaired circulation, or ultraviolet and infrared irradiation could be causative factors in electric cataract.

In our first case we found three circumscribed skip retinal lesions. These lesions are produced by electrical current when it passes through any structure of the body. There are some reports in various journals regarding the skip lesion:

- Gregory ${ }^{9}$ et al. showed that 'damage to the internal structures of the body may be spotty, with areas of normal-appearing tissue adjacent to burned tissue and with damage to structures at sites distant from the apparent contact points. Electrothermal heating is the main cause of muscle damage and is almost exclusively seen in high voltage accidents with prolonged (seconds) contact and current flow. The histologic change seen in muscle injury that results from direct contact with an electrical source is coagulation necrosis with shortening of the sarcomere. Muscle damage can be spotty, so areas of viable and nonviable muscle are often found in the same muscle group.'

- Marry ${ }^{10}$ et al. showed preretinal fibrosis and chorioretinal atrophy surrounding the optic nerve and two smaller regions superonasal and inferotemporal lesion of one of their patients. Results of optical coherence tomography (OCT) correlated with fundus examination findings, showing retinal thinning and retinal pigment epithelium/choriocapillary irregularity in the area adjacent to the optic nerve.

- Jin ${ }^{11}$ et al. reported a case of retinal lesion due to electric injury which showed axial symmetrical meridional atrophies around the optic disk in both eyes in the patient's fundus fluorescein angiography and indocyanine green angiography image.

- Al Rabiah ${ }^{12}$ et al. showed after histopathological examination that the retinal lesion contained relatively intact retinal neuropile although the retinal and choroidal circulations were severely compromised. Electroretinographic tests and pseudo-random binary stimulus visually evoked responses were useful in predicting the visual outcome.

In conclusion, high-voltage electrical injury usually causes unilateral cataract because current passes through a straight line connecting wound of contact and wound of exit and the affected eye but it can cause bilateral cataract earliest site is ipsilateral to the site of impact. Outcomes after surgery are very good if not associated with other ocular lesion like optic atrophy, retinal lesion, uveitis etc. 


\section{References}

1. Dilraj Singh Grewal, Rajeev Jain, Gagandeep Singh Brar, Satinder Pal Singh Grewal. Unilateral electric cataract: Scheimpflug imaging and review of the literature. J Cataract Refract Surg 2007;33:1116-1119.

2. Saint Yves $C$. Les causes accidentelles qui peuvent blesser la vue. In: Nouveau Traité des Maladies des Yeux, les Remedes qui y Conviennent, \& les Opérations de Chirurgie que Leurs Guérisons Exigent. Paris, France, Pierre-Augustin Le Mercier 1722;368-370. (Cited by Duke-Elder S. Textbook of Ophthalmology. St Louis, MO: Mosby 1954; vol. 6:6435-6442).

3. Bailey B, Forget $S$, Gaudreault P. Prevalence of potential risk factors in victims of electrocution. Forensic Sci Int 2001;123:58-62.

4. Hanna C, Fraunfelder FT. Electric cataracts. II. Ultrastructural lens changes. Arch Ophthalmol 1972;87:184-191.

5. Fraunfelder FT, Hanna C. Electrical cataracts. I. Sequential changes, unusual and prognostic findings. Arch Ophthalmol 1972;87:179-183.

6. Hess C. Experimentelles über Blitzcataract (Vorlaüfige Mitteilung). 7e Internationale Congress, Heidelberg, den 8-11 August 1888. Wiesbaden, Germany: JF Bergmann 1888;308-317.

7. Croci L. Cataratta elettrica sperimentale. Atti del Congresso della Societa Oftalmolologica Italiana, Parma 31st, 1932;3.

8. Kiribuchi K. Experimentelle Untersuchungen über Cataract und sonstige Augenaffektionen durch Blitzschlag. Albrecht von Graefes Arch Ophthalmol 1900;50:1-43.

9. Zablocki G, Hagedorn C. Chorioretinal atrophy after electrical injury. Digital Journal of Ophthalmology 2011;17(3).

10. Cooper MA, Price TG. Electrical and Lightning injury. www.uic.edu/labs/lightninginjury/Electr\&Ltn.pdf.

11. Jin CJ, et al. Electrical injury induced bilateral peripapillary meridional retina-choroidal atrophy: A case report. Retinal cases \& brief reports 2011;5(3): 237-240.

12. Al Rabiah $\mathrm{SMH}$, et al. Electric injury of eye. International Ophthalmology Volume 11, Number 1, 31-40 


\section{Xalatan: $\mid$ Xalacom}

\section{Efizer}

\section{One Drop a day helps them see what matters most..$^{1-4}$}

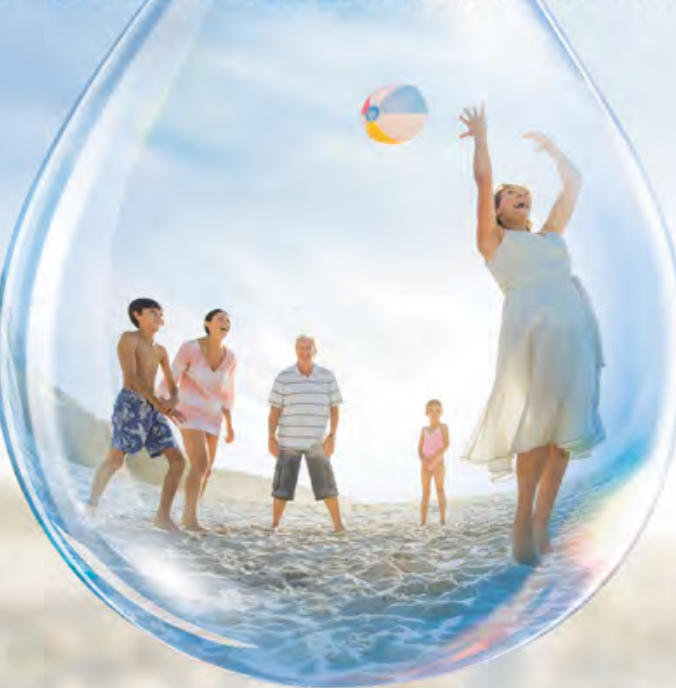

For over 10 years, Xalatan $^{\circledR}$ and Xalacom ${ }^{\circledR}$ have offered patients effective glaucoma treatments with the convenience of one bottle, one drop, once a day. ${ }^{1-4}$

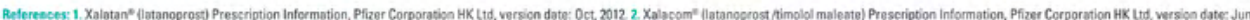

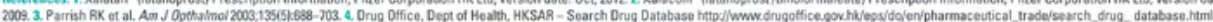

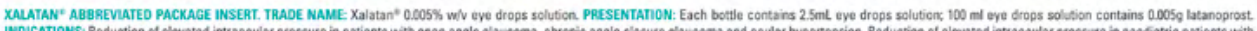

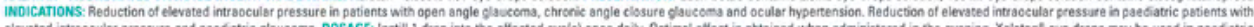

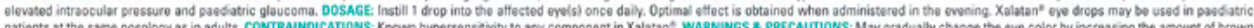
patients st the same posology as in adults. CONTRAUNOICANONS: Known hypersensitivity to any component in Xalatant. WARNiNGS \& PRECAUTIONS: May gradually change the eve color by increasing the amount of brown pigment in the inis. Patients should be monitored regularly and if the clinical situasion warrants, Xalazan" treatment may be discontinued. Xalatan* should be esed with caution in peri-operative peciod of cataract surgery patients, patients with a history of herpebic kerautis, aphakie pabents, in pseudophatic patients with torn posterior lens capsule or anterior chamber lenses, or in pubients with knowa risk factors for cystoid macular cedema, asthmatic patients. Experience to date shows that periorbital skin discolouration is not permanemt. Latanoprost may gradually champe evelashes and vellus hair in the treated eye and surrounding areas. Xalatan" contain. benzalkorium chloride. Contact lenses may sbsorb benzalkonium chloride and these should be removed before appiving Xalatan" but may be reinserted after 15 minutes. Ellicacy and safecty data in the age group < 1 year are

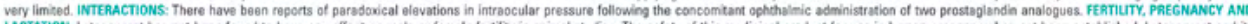
LACTarioN: Latanoprost hes not been found to have any effect on male or femele fertily in anima/ studes. The safeey of this medicinal product for use in human pregnency hes not been estabished. Latanoprost and its metabolites may pass into breast milk and Xalatan?" should therefore not be used in nutsing women of bresst feeding should be stopped. SiDE EFFECTs: Incteased iris pigmentation, mild to moderate conjunctival hyperaemila

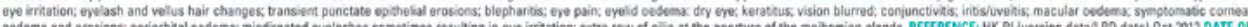

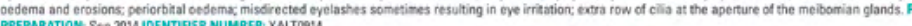

XULACOM" ABEAEVIATED PACKAGE INSERT. TRADE NAME: Xalacom" eye drops, solution 2.5mL, PRESENTATION: Each mi of Xalacom" contains 50meg latanoprost and $5 \mathrm{mg}$ timdlol. INDICATIONS: Reduction of imraoculat

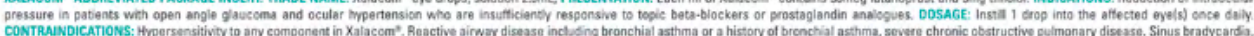

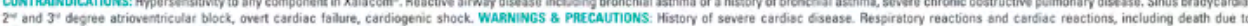

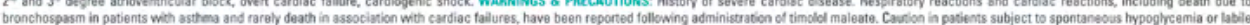

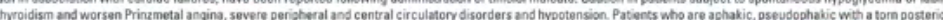
lens capsule or with known risk factors for macular oedema. Mary cause change in eve colour. Coenact lenses should be removed before asministration and mayte reinserted after 15 minutes INTERACTioNs: The use of twe

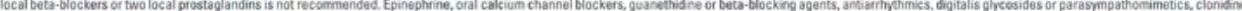

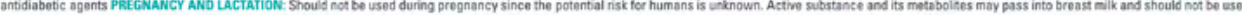

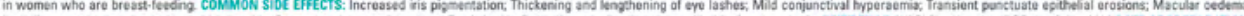

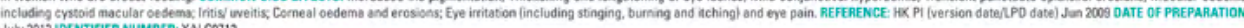
JUlY 2012 IOEENTFER NUMBBER: XALCO712

FULL PRESCRIBING INFORMATON IS AVAILABLE UPON REOUEST. 


\section{Asian Journal of}

Volume $13 \cdot$ Issue $4 \cdot 2014 \cdot 1560-2133$

www.asjoo.com www.kuglerpublications.com 